\title{
QUEEN'S
UNIVERSITY
BELFAST
}

\section{Effect of mix proportions on rheology and permeability of cement grouts containing viscosity modifying admixture}

Sonebi, M., \& Perrot, A. (2019). Effect of mix proportions on rheology and permeability of cement grouts containing viscosity modifying admixture. Construction and Building Materials, 212, 687-697.

https://doi.org/10.1016/j.conbuildmat.2019.04.022

\section{Published in:}

Construction and Building Materials

\section{Document Version:}

Peer reviewed version

\section{Queen's University Belfast - Research Portal:}

Link to publication record in Queen's University Belfast Research Portal

\section{Publisher rights}

Copyright 2019 Elsevier

This manuscript is distributed under a Creative Commons Attribution-NonCommercial-NoDerivs License

(https://creativecommons.org/licenses/by-nc-nd/4.0/), which permits distribution and reproduction for non-commercial purposes, provided the author and source are cited.

\section{General rights}

Copyright for the publications made accessible via the Queen's University Belfast Research Portal is retained by the author(s) and / or other copyright owners and it is a condition of accessing these publications that users recognise and abide by the legal requirements associated with these rights.

Take down policy

The Research Portal is Queen's institutional repository that provides access to Queen's research output. Every effort has been made to ensure that content in the Research Portal does not infringe any person's rights, or applicable UK laws. If you discover content in the Research Portal that you believe breaches copyright or violates any law, please contact openaccess@qub.ac.uk. 


\title{
Effect of mix proportions on rheology and permeability of cement grouts containing viscosity modifying admixture
}

\author{
Mohammed Sonebi*, Arnaud Perrot \\ *Queen's University Belfast, School of Natural and Built Environment., Belfast, BT7 \\ $1 \mathrm{NN}, \mathrm{UK}$ \\ University of South Brittany, Lorient, France
}

\begin{abstract}
This paper reports the effect of mix composition of grout on the fluidity, rheological behaviour and hydro-mechanical behaviour (permeability and compressibility). Factorial design was used in this investigation to assess the combined effects of the four mix composition parameters on fluidity, rheological properties, permeability and compressibility: water/binder ratio (W/B), percentage of limestone filler as replacement of cement (LF), dosage of viscosity modifying admixture (VMA), and dosage of superplasticiser (SP). To evaluate both the rheology of the cement grout and its hydro-mechanical behaviour, mini-slump test, Lombardi plate test, and forced bleeding test, coaxial rotating cylinder viscometer were used. A two-level fractional factorial model was used to model the effect of key variables on the fluidity, the cohesion, permeability and compressibility. The predicted models are valid for mixtures made with W/B ranged from 0.35 to 0.42 , LF from $12 \%$ to $45 \%$ as replacement of cement, VMA (percentage of binder) from 0.02 to $0.7 \%$, and SP from 0.3 to $1.2 \%$. The effects of $\mathrm{W} / \mathrm{B}, \mathrm{LF}, \mathrm{VMA}$ and SP were analysed using polynomial regression which can identify the primary factors and their interactions on the measured properties. Prediction models were developed for mini-slump, plate cohesion meter, permeability and compressibility as function of W/B, LF, VMA, and SP. The factorial statistical approach used highlighted the effect of $\mathrm{W} / \mathrm{B}$, the dosages of SP and VMA on the various rheological properties, permeability and compressibility.
\end{abstract}


Keywords: compressibility; limestone filler; mini-slump; permeability; rheology; superplasticiser; viscosity modifying admixture; water/binder.

\section{Introduction}

Cement grouting injections are involved in many operations in the field of civil engineering and construction: soil consolidation, coating of prestressed cables, maintenance and repair of masonry and concrete structures, and widely used in injection grouting of cracks in massive structures [1-6]. Cementitious grouts are being used for several existing structures, and are able to withstand gravity effects thanks to developments which have been made possible through the use of cement cementitious materials and chemical admixtures [7-14]. Viscosity modifying admixtures (VMAs) are used to enhance the cohesion, viscosity and stability of cement-based materials. They are generally water-soluble polysaccharides, synthetic or semi-synthetics that enhance the water retention capacity of paste. VMAs have proved to be very effective in stabilizing rheological properties and fluidity of cement grout, self-compacting concrete, and underwater concrete [7, 9, 10-14].

Recently, cement grouts have also been used for 3D printing operations by selective paste intrusion $[15,16]$. During the injections, the cement grout must be fluid enough to fill a cavity or to penetrate into a porous network. Moreover, the material has to remain homogeneous during the grouting especially for high pressure injection.

In order to mix-design fluid and stable grouts, Rosquoet at al. [5] have studied the properties of grouts at fresh state: their sedimentation behaviour and their rheological behaviour. The authors have used both coaxial cylinder rheological measurements and $1.5 \mathrm{~m}$ meter high sedimentation column under self-weight in order to estimate the ability of the grouts to remain homogeneous. The authors have shown that for high W/C ratio (higher than 0.5 ), the grouts become heterogeneous while for low W/C ratio (lower than 0.5 ), the lack of fluidity may hinder injection operations. Therefore, it seems that the mix-design of cement grouts needs a compromise between fluidity and homogeneity.

Bleeding and force bleeding tests can be used to estimate the ability of the grouts to remain homogeneous $[17,18]$. In this case, the ability of cementitious material to remain homogeneous can be studied using classical consolidation theory used in soil mechanics. Recent studies have demonstrated that it is possible to use 
force bleeding in order to measure the permeability of cement-based materials and also its compressibility (the amount of bleed water under an applied pressure) [19-22]. These parameters can be very useful in order to predict the amount of bleed water and the kinetics of this filtration. In this study, such approach will be used in order to study the ability of the grout to remain homogeneous.

The aim of this paper is to investigate the effect of water-to-binder ratio, the percentage of limestone filler (LF) replacement of cement, and the dosages of VMA and SP on the rheological properties and the permeability and compressibility of grouts using a factorial design approach [23-25]. The mini-slump test, Lombardi plate, and forced bleeding test were used to test the behaviour of fresh cement grouts. The established models can identify parameters and the two-way interactions that have significant effect on the rheological properties and hydro-mechanical behaviour of grouts. The models can be used to evaluate the potential influence of adjusting mix variables on grout properties required to ensure successful development of grout. Such simulation can facilitate the test protocol needed to optimize grout with a given set of performance criteria that can be tried in the laboratory.

\section{Statistical design approach}

The technique of analysis used in this study was $2^{4-1}$ fractional statistical experimental design $\left(2^{\mathrm{k}-1}=8\right)$ to evaluate the influence of two different levels for each independent variable (maximum and minimum) on the relevant grout properties. Four key parameters $(\mathrm{k}=4)$ that can have significant influence on mix characteristics of cement grout were selected to derive mathematical models for evaluating relevant properties. The four key variables were (W/B, \% of LF, dosages of VMA and SP) that should have significant influence on mix characteristics of cement grouts were selected to formulate the mathematical models for evaluating relevant properties. The derived statistical models are valid for mixes made with ranges of W/B of 0.35 to $0.42, \%$ of LF from 12 to $45 \%$, the dosages of VMA of 0.02 to $0.07 \%$, by mass of binder (or $0.057 \%$ to $0.166 \%$ of water), and SP of 0.3 to $1.2 \%$, by mass of binder (Table 1).

Additionally, a mix at the central point was replicated four times to estimate the experimental error and improve the reliability of the models. 
The fresh cement grouts were tested with mini-slump test, Lombardi plate, and viscometer and forced bleeding test. In total, 12 selected mixes considered in the factorial design are listed in Table 2.

The responses modelled were mini-slump, plate cohesion, yield stress, plastic viscosity, permeability and compressibility. The general model associated with the two-level factorial design incorporating three independent variables (W/B, LF, VMA, $\mathrm{SP})$ is expressed by:

$$
Y_{1}=a_{0}+a_{1} \mathrm{~W} / \mathrm{B}+a_{2} \mathrm{SP}+a_{3} \mathrm{LF}+a_{4} \mathrm{VMA}+a_{5} \mathrm{~W} / \mathrm{B} \cdot \mathrm{SP}+a_{6} \mathrm{~W} / \mathrm{B} \cdot \mathrm{LF}+a_{7} \mathrm{~W} / \mathrm{B} \cdot \mathrm{VMA}+\varepsilon
$$

$\mathrm{Y}_{1}$ : Response (mini slump, plate cohesion, yield stress, plastic viscosity, permeability, compressibility)

$\mathrm{a}_{0}$ : Overall mean factor effect

$\mathrm{a}_{1}-\mathrm{a}_{7}$ : Regression coefficients representing model constants (contribution of independent variables and their interaction to each response)

$a_{1} \cdot W / B, a_{2} \cdot S P, a_{3} \cdot L F, a_{4} \cdot V M A$ : Linear effect of factors W/B, SP, LF and VMA

$\mathrm{a}_{5} \cdot \mathrm{W} / \mathrm{B} \cdot \mathrm{SP}, \mathrm{a}_{6} \cdot \mathrm{W} / \mathrm{B} \cdot \mathrm{LF}, \mathrm{a}_{7} \cdot \mathrm{W} / \mathrm{B} \cdot \mathrm{VMA}$ : Interaction effects of factors W/B, SP, VMA and LF.

$\varepsilon$ : Random error term representing the effects of uncontrolled variables

To study statistically the results, analysis of variance (ANOVA) was used to test the significance of regression models, and t-tests were performed to identify the nonsignificant (NS) variables and second order interactions, which were subsequently eliminated from the derived models. The coefficients of the modes were determined using multi-linear regression analysis based on a normal distribution assumption. The error was assumed to be random and normally distributed, so the residual terms, which represent the difference between the actual and predicted values should exhibit similar properties [23]. The probability value (Prob.) obtained from ANOVA analysis determines the statistical significance of each factor and their interactions. For most of the parameters, the probability that the derived coefficients associated with the various variables which influence each response were limited to $10 \%$. This signifies that there is less than $10 \%$ chance or $90 \%$ confidence limit that the contribution of a given parameter to the tested response of the property of grout exceeds the value of the specified coefficient. A negative estimate indicates that an increase of the given parameter results in a reduction of the measured response. 


\section{Material proportions and testing procedures}

The grouts used in this study were made with ordinary Portland cement and limestone filler. The cement was Portland cement type CEM I 42.5N, as specified by the standard EN 197-1:2000 [26]. The chemical and physical properties of cement and limestone filler are presented in Table 3. The limestone filler was produced from carboniferous limestone of a very high purity and was finer than cement. The limestone filler had grading of $98 \%$ less than $45 \mu \mathrm{m}$ and $25 \%$ less than $5 \mu \mathrm{m}$. The particle size distributions of cement and limestone filler are given in Fig. 1.

The superplasticiser used was a modified polycarboxylate with a solid content of $30 \%$ and specific gravity of 1.11 . The viscosity modifying admixture was welan gum that is a high molecular weight, microbial polysaccharide.

All grout mixes were prepared in a 5-litre planar-action mortar mixer. The mixing tap water had a temperature of $16 \pm 1^{\circ} \mathrm{C}$, which was measured before mixing started. The VMA was mixed with cement. The SP was added to the water and mixed together. Mixing time was measured from when the limestone filler (the first solid component) was added into the mix of water and SP. Finally, the mix of cement and VMA was added and all components were mixed for seven minutes from the start of measuring time. The grout temperature following the end of mixing was maintained at $20 \pm 2^{\circ} \mathrm{C}$.

At the end of mixing, the temperature and unit weight of the grout were measured. The grout temperature at the end of mixing was for all mixes $14.0 \pm$ $0.2{ }^{\circ} \mathrm{C}$. Mini-slump, plate cohesion, rheological parameters and induced bleeding were also measured at 1-2, 4-5, 6-8, and 9-10 minutes, respectively. All tests were carried out in the 5 to 15 minutes following the initial contact of binder with water and were performed in the same sequence.

A mini-slump cone with an upper diameter of $19 \mathrm{~mm}$, a lower diameter of 38.1 $\mathrm{mm}$, and height of $57.2 \mathrm{~mm}$ [27] was used. The test procedure measured the spread diameter of $38 \mathrm{ml}$ of grout placed in the cone. The spread diameter of a given mix represents the mean of two perpendicular diameters recorded at the end of the flow. The cone was positioned at the centre of the horizontal base plate. After pouring the grout into the cone without overflow, the upper part of the cone was tamped lightly to bleed off any air pockets, and the entire cone was gently lifted. 
The cohesiveness of the grout was measured with a Lombardi plate cohesion meter [28], an apparatus that consists of a thin steel plate (100 mm x $100 \mathrm{~mm} \times 1 \mathrm{~mm})$ and an electronic scale. The clean dry steel plate was weighed, submerged into the slurry, withdrawn from the paste, and weighed again after the grout had stopped dropping. It was possible to calculate the thickness of the grout on each side of the Lombardi plate from the unit weight and the amount of grout sticking to the steel plate. An increase in the plate cohesion corresponded to more cohesive grout.

The specific weight of the grout was measured by a mud balance. This mud balance consists of a constant-volume sample cup with lid connected to a balance arm. A reader is moved along the balance arm to indicate the scale reading. There is a knife edge attached to the arm near the balance cup and a bubble level built into this knife edge for levelling the arm. It was possible to calculate the thickness of grout on each side of the plate from the unit weight and the amount of grout sticking to the steel plate.

The resistance of the fresh grout to induced bleeding was evaluated using a pressure filter. The equipment consists of a pressure vessel, filter paper, which is placed on a sieve, and a graduated cylinder. A $200 \mathrm{ml}$ grout sample is placed in the pressure vessel. After closing the cell, the graduated cylinder is placed under the outlet of the cell. The cell is pressured by compressed air to $0.55 \mathrm{MPa}$. The volume of water going out through the outlet on the bottom of the cell is recorded at 15 and $30 \mathrm{~s}$, then at every minute up to $10 \mathrm{~min}$, and then at every $5 \mathrm{~min}$ up to $30 \mathrm{~min}$ [29]. The result of this test at 30 was used to calculate the permeability.

From the results of the induced bleeding, it is easily to compute the masses and volumes of water and solid particles. For example, for cement/water mixes, assuming that the grout is fully saturated by using the following equations (1 to 4) [30]:

$$
\begin{aligned}
& V_{\text {cement }}=\frac{V_{\text {sample }}}{1+\frac{W}{C} * \frac{\rho_{\text {cement }}}{\rho_{\text {water }}}} \quad \text { (1) } \quad m_{\text {cement }}=\frac{\rho_{\text {cement }} V_{\text {sample }}}{1+\frac{W}{C} \frac{\rho_{\text {cement }}}{\rho_{\text {water }}}} \\
& V_{\text {water }, t=0 s}=V_{\text {sample }}\left(\frac{\frac{W}{C} * \frac{\rho_{\text {cement }}}{\rho_{\text {water }}}}{1+\frac{W}{C} * \frac{\rho_{\text {cement }}}{\rho_{\text {water }}}}\right) \text { (3) } \quad m_{\text {water }, t=0 \text { s }}=\rho_{\text {water }} V_{\text {sample }} \frac{\frac{W}{C} \frac{\rho_{\text {cement }}}{\rho_{\text {water }}}}{1+\frac{W}{C} \frac{\rho_{\text {cement }}}{\rho_{\text {water }}}}
\end{aligned}
$$


With $V_{\text {water }, t=0 s}$ and $m_{\text {water }, t=0 s}$ are the initial water volume, mass $\rho_{\text {cement }}$ and $\rho_{\text {water }}$ are the densities of the cement and water respectively, $V_{\text {cement }}$ and $V_{\text {sample }}$ are the volumes of cement and of the tested samples and $W / C$ is the water to cement mass ratio.

The liquid flow rate $Q$ can be calculated from the difference between two measurements of mass $\Delta V_{\text {sample }}$ which can be attributed to water drainage $\Delta V_{\text {water }}$ in a given period of time $\Delta t(\mathrm{Eq} .5)$

$$
Q=\frac{\Delta V_{\text {sample }}}{\Delta t}=\frac{\Delta V_{\text {water }}}{\Delta t}
$$

The liquid drainage induces a reduction of the average water content $\Delta m_{\text {water }}$ of the grout (Eq. 6):

$$
\Delta m_{\text {water }}=\rho_{\text {water }} \Delta V_{\text {water }}=Q \rho_{\text {water }} \Delta t
$$

Therefore, the new value of W/C for the next measuring point can be calculated (Eq. 7)

$$
\frac{W}{C}(t)=\frac{m_{\text {water }, t=0 s}-\Delta m_{\text {water }}}{m_{\text {cement }}}
$$

With $m_{\text {cement }}$, the cement mass inside the tested sample. Finally, the permeability coefficient $k$ can be computed from two consecutive measuring points using the Darcy Law (Eq. 8):

$$
k=\frac{Q}{S . i}
$$

Where $S$ is the section of the sample of diameter $D$ and $i$ is the hydraulic gradient which can be written as follow (Eq. 9):

$$
i=\frac{P}{\rho_{\text {water }} g H_{\text {sample }}}
$$

Where $P$ is the applied pressure, $H_{\text {sample }}$ is the sample height and $g$ is the gravity. It is important to note that the variation of the sample height can be easily taken into account as the volume variation of the sample during the test is known.

It is important to note that when the value of $Q(<0.1 \mathrm{ml} / \mathrm{s})$ is too small, the permeability value can't be computed (inaccurate computation).

The compressibility index $\lambda$ of the Terzaghi consolidation theory can also be calculated from the data using Eq. 10: 


$$
\lambda=\frac{\Delta e}{\ln (P)-\ln \left(\rho g H_{\text {sample }}\right)}=\frac{\rho_{\text {cement }}}{\rho_{\text {water }}} \frac{\Delta(W / C)}{\ln (P)-\ln \left(\rho g H_{\text {sample }}\right)}
$$

With $\Delta e$, the variation of the sample void ratio.

The viscosity of cement grout was determined using a coaxial viscometer Fann (smooth cylinders, no serration) that determined apparent viscosity at different shear rates $[9,13]$. The test was contained in the annular space between an outer cylinder (rotor) with a radius of $18.42 \mathrm{~mm}$ and a bob with a radius of $17.25 \mathrm{~mm}$ and a height of $3.80 \mathrm{~cm}$. The rotor and bob were plunged into a cup containing $350 \mathrm{ml}$ of sample grout $[9,13]$. Viscosity measurements were made when the outer cylinder, rotating at a known speed, caused a viscous drag to be exerted by the fluid. This drag created a torque on the bob, which was transmitted to a precision spring, where its deflection was measured and compared with test conditions and the instrument's constants.

The yield value measured using the co-axial cylinder was largely independent of rotational speed, and due to a water-rich slip layer, which forms during testing $[9,13]$, had a solids concentration lower than bulk materials. In this study, the down-curve was chosen for final evaluation because it offered a better description of the rheological behaviour of the grouts, including a structural breakdown phenomenon of inner forces among particles [31]. The values of yield stress and plastic viscosity used the modified Bingham model [9] and are expressed in Eq. (11).

$$
\tau=\tau_{0}+\mu_{p} \dot{\gamma}+c \dot{\gamma}^{2}
$$

Where $\tau_{0}$ is yield stress $(\mathrm{Pa}), \mu_{p}$ is plastic viscosity $(\mathrm{Pa} \cdot \mathrm{s}), \dot{\gamma}$ is shear rate $\left(\mathrm{s}^{-1}\right)$, and $c$ is a constant.

\section{Test results and discussion}

\subsection{Derived statistical models}

The presentation in Table 4 enables the comparison of various parameters as well as the interactions of the modelled responses. For the majority of parameters, the probabilities that the derived coefficients of the various parameters influence each response are limited to $10 \%$. This signifies that there is less than $10 \%$ chance or $90 \%$ confidence limit, that the contribution of a given parameter to the tested response exceeds the value of the specified coefficient. A negative estimate signifies that an increase of the given parameter results in a reduction of the measured response. 
For example, mini-slump, plate cohesion meter, yield value, plastic viscosity, permeability and compressibility are given in codes values in Eq. (12-17), respectively.

$$
\begin{aligned}
\text { Mini-slump }(\mathrm{mm})= & 113.2+31.3 \cdot \mathrm{SP}+21.4 \cdot \mathrm{W} / \mathrm{B}-17.6 \cdot V M A+12.8 \cdot \mathrm{LF} \\
& +11.9 \cdot \mathrm{W} / \mathrm{B} \cdot \mathrm{SP}
\end{aligned}
$$

Ln Plate cohesion meter $(\mathrm{mm})=-0.87-0.93 \cdot \mathrm{SP}+0.56 \cdot \mathrm{VMA}-0.37 \cdot \mathrm{W} / \mathrm{B}$

$$
-0.32 \cdot L F+0.27 \cdot W / B \cdot L F
$$

$1 /$ Yield value $(P a)=0.18+0.087 \cdot S P-0.063 \cdot V M A+0.018 \cdot W / B$

$-0.10 \cdot W / B \cdot L F-0.022 \cdot W / B \cdot V M A$

$1 /$ Plastic viscosity $($ Pa.s $)=4+1.91 \cdot W / B+1.45 \cdot S P-1.28 \cdot V M A+0.84 \cdot L F$

$$
0.58 \cdot W / B \cdot S P
$$

$$
\begin{aligned}
\text { Permeability }(\mathrm{m} / \mathrm{s}) \times 10^{8}= & 13.2-7.7 \cdot \mathrm{SP}+2.38 \cdot \mathrm{W} / \mathrm{B}+1.15 \cdot \mathrm{VMA} \\
& -2.63 \cdot \mathrm{W} / \mathrm{B} \cdot \mathrm{SP}+2.31 \mathrm{~W} / \mathrm{B} \cdot \mathrm{VMA}
\end{aligned}
$$

$1 /$ Compressibility $=6.55-0.95 \cdot S P-0.56 \cdot \mathrm{W} / \mathrm{B}+0.39 \cdot \mathrm{VMA}-0.58 \mathrm{~W} / \mathrm{B} \cdot \mathrm{LF}$

The correlation coefficients of the proposed models for mini-slump test, plate cohesion, yield value, plastic viscosity, permeability and compressibility of grouts are $0.85,0.95,0.85,0.94,0.98$ and 0.93 , respectively. The high correlation coefficient of most responses demonstrates excellent correlation where it can be considered that at least $90 \%$ of the measured values can be accounted for with the proposed models.

Table 5 indicates the average measured response of the four replicate grouts, coefficient of variation, estimated error with $90 \%$ confidence limit, as well as relative error for each of the measured properties. The estimate error of cement grout for mini-slump, plate cohesion meter, yield value, plastic viscosity, permeability, and compressibility were $\pm 5.3 \mathrm{~mm}, \pm 0.05 \mathrm{~mm}, \pm 0.49 \mathrm{~Pa}, \pm 0.02 \mathrm{~Pa} . \mathrm{s}, \pm 0.11 \times 10^{-7} \mathrm{~m} / \mathrm{s}$, \pm 0.01 , respectively.

\subsection{Isoresponses of the proposed models of the key variables}

The proposed statistical models can therefore be used to evaluate the effect of a group of variables on the properties affecting the quality of cement grout. This permitted the calculation of the isoresponse curves from the parameters under study over the experimental domain and the optimisation of their effects. 


\subsubsection{Mini-slump}

As shown in Eq. 12, mini-slump was influenced, in order of magnitude, by SP, W/B, VMA dosage, and by the percentage of LF. There was also effect of interaction of W/B and SP on fluidity. SP dosage had the greatest effect on mini-slump results due to steric repulsions among cement particles that react with SP, which led to a better deflocculation of the particles in the cement paste [10, 32, 33]. The mini-slump test was accompanied by very low shear and it is to characterise yield stress $[34,35]$, therefore higher mini-slump value indicated a lower yield stress values. The effect of VMA on the reduction of fluidity was slightly higher than increased LF (-17.6 vs. 12.8). The increase in SP affected mini-slump approximately 2.5 times more than the increase in LF content (31.3 vs. 12.8 in Eq. 12). However, increased W/B resulted in a 1.2 times greater increase in mini-slump than reduced VMA (21.4 vs. -17.6 in Eq. 12). Fig. 2(a) shows the effect of increased SP on mini-slump vs. W/B (when VMA was kept constant at $0.05 \%$ and $\mathrm{LF}=28.5 \%$ ), and Fig. 2(b) shows SP vs. VMA (when W/B was fixed at 0.39 and $\mathrm{LF}=28.5 \%$ ). Fig. 2(c) presents the variation of minislump SP vs. LF (when W/B was fixed at 0.39 and VMA $=0.05 \%$ ).

Based on these figures, it is evident that mini-slump increased significantly when the dosage of SP. Similarly, mini-slump increased when W/B or LF increased. However, VMA increased led to a reduction of mini-slump. For any a given VMA and SP dosage, the fluidity was found to increase when LF level increased. This is likely due to both the inert particles of LF and a favourable modification of the particle packing due to a broader particles size distribution (PSD) [36]. It appears that PSD of binder can play a major role in changing the rheology of cement grouts. Hence, using broader PSD leads to an increase in the maximum dense packing fraction and therefore a decrease in yield stress [37]. Using ternary binder system with different PSD of each constituent can be very efficient to design dense (low permeability) and fluid (solid volume fraction far from the dense packing fraction) grout. Such studies will be carried out in further works.

In Eq. 12, the dosage of SP and W/B caused an interaction effect $(+11.9)$. On the other hand, mini-slump decreased when the dosage of VMA increased from $0.02 \%$ to $0.07 \%$ (Fig. 2(b)), while SP, LF and W/B were kept constant.

\subsubsection{Plate cohesion meter}


As shown in Eq. 13, the cohesion plate was influenced, in order of magnitude, by the dosages of SP, VMA, W/B and LF. The increasing percentage of W/B had almost similar the influence on the reduction of the cohesion plate test results as LF (for W/B and VMA constant, -0.37 vs. -0.32). By comparing the effects of SP and VMA on plate cohesion, the increased SP can be interpreted as having approximately a 1.7 times greater influence on the reduction of plate cohesion values than the increase in VMA (-0.93 vs. 0.56 in Eq. 13), given that LF and W/B are held constant. The effect of an increase in SP from $0.3 \%$ to $1.2 \%$ and W/B from 0.35 to 0.42 with a fixed VMA dosage of $0.05 \%$ and $\mathrm{LF}=28.5 \%$ is presented in Fig. 3(a). Increased SP led to a reduction cohesion plate value. An increase in LF reduced the cohesion plate value and similarly an increased W/B caused also a decrease in cohesion plate (Fig. 3(b)). Fig. 3(c) presents the effect of SP vs. VMA on the variation of plate cohesion when LF is fixed at $28.5 \%$ and $\mathrm{W} / \mathrm{B}$ at 0.39 . As expected, it can be noticed that the increase of VMA led to an increase of plate cohesion value.

\subsubsection{Yield stress}

As shown in Eq. 14, the predicted model is primarily affected by the dosages of SP, VMA and W/B. The interaction between W/B and LF and W/B and VMA also influenced the yield stress. The reduction in the dosages of SP or increase of VMA led to increasing the yield stress values (Fig. 4), corresponding to lower mini slump values. The increase in the SP dosage has an approximately 1.4 times greater influence on reducing the yield stress than the decreasing in VMA $(+0.087$ vs. 0.063). Adding SP increases the surface coverage of cement and limestone particles by polymer causing steric hindrance and consequently weaker van der Waals attraction between the particles; therefore, smaller forces are needed to disperse the particles resulting in lower yield stress [38]. VMA increased the yield stress due to the entanglement and intertwining of VMA polymer chains and association of water between adjacent chains (Fig. 4 (c)) [9, 11, 13]. Moreover, VMA can promote bridging flocculation between cement and limestone particles leading to yield stress increase [39, 40, 41]. This mechanism is likely to occur because the SP dosage is below full coverage that leaves free surface to the VMA to adsorb. Furthermore, depletion flocculation mechanism could additionally contribute to the observed increase of yield stress and loose of fluidity of the grouts. 
Fig. 4 (a) shows the isoresponse curve of the yield value with a fixed proportion of LF at $28.5 \%$ and VMA at $0.05 \%$. When SP dosage was $0.75 \%$ and W/B was 0.35 , the isoresponse of the predicted yield value was $5 \mathrm{~Pa}$. If SP was increased to $1.2 \%$ while maintaining W/B at 0.35 , the isoresponse of the yield value was approximately 4.1 Pa. Fig. 4 (b) presents the isoresponse of yield stress of W/B vs. LF when SP is fixed at $0.75 \%$ and VMA at $0.05 \%$. In this case, the yield stress seemed to reduce with increased W/B up 0.39, then tended to increase beyond this threshold value. For fixed dosages of SP and VMA, the yield value decreased significantly up to about 0.39 of W/B and higher percentage of LF (up to 29\%). At higher percentage of LF, however, an increase of yield value was observed with an increase in W/B from 0.39 to 0.42 (Fig. 4 (b)). Such results is surprising and can be due to uncertainty when measuring low yield stress values. It is interesting to note that yield stress, slump flow and plate tests provide close response. This is expected as all three parameters can be considered to be closely linked [7, 8, 13, 14, 35, 37].

\subsubsection{Plastic viscosity}

Plastic viscosity was influenced, in order of magnitude, by W/B ratio, the dosages of SP, VMA and LF and an interaction of W/B and SP. W/B had approximately 1.3 times effect on plastic viscosity than SP (1.91 vs. 1.45 in Eq. 15). As shown in Eq. (15), increased of dosage of SP had a greatest effect on plastic viscosity compared to VMA (1.45 vs. 1.28). The increased VMA had higher influence on reducing plastic viscosity than increased LF (-1.28 vs. 0.84$)$.

In the isoresponse curves of plastic viscosity shown in Fig. 5 (a), when VMA was fixed at $0.05 \%, \mathrm{LF}$ set at $28.5 \%$, and SP maintained at $0.75 \%$, the predicted plastic viscosity value was $0.4 \mathrm{~Pa}$.s when $\mathrm{W} / \mathrm{B}$ fixed at 0.35 . On the other hand, if the dosage of SP was increased to $1.2 \%$ while maintaining a similar proportion of SP, the plastic viscosity was reduced to $0.3 \mathrm{~Pa}$.s. It appears that the lowest plastic viscosity was obtained with approximately $0.42 \mathrm{~W} / \mathrm{B}$ and $1.2 \%$ SP.

In Fig. 5 (b), SP was fixed at $0.75 \%$ and VMA at $0.05 \%$. When LF was held at $28.5 \%$ and $\mathrm{W} / \mathrm{B}$ at 0.35 , the predicted plastic viscosity was 0.4 Pa.s. However, when LF was increased to $45 \%$ and W/B was maintained at 0.35 the predicted plastic viscosity dropped to 0.3 Pa.s. In Fig. 5 (c), the proportion of LF was fixed at $28.5 \%$, if the dosage of VMA is held at $0.02 \%$ while the dosage of SP used at $0.75 \%$ and W/B at 0.35 , the predicted plastic viscosity is 0.27 Pa.s. In the case of VMA is increased to 
$0.07 \%$ and the $\mathrm{W} / \mathrm{B}$ is maintained at 0.35 , the predicted plastic viscosity increased to 0.70 Pa.s.

In this case, the effect of LF can be explained by increase in the dense packing volume fraction of the binder according to the Krieger Dougherty prediction modelling [42]. LF has slightly smaller particles that broaden the particles size distribution of the binder and then increase the dense packing volume fraction. It can be interesting that such results should also have been reported for yield stress whatever the $\mathrm{W} / \mathrm{B}$ ratio.

\subsubsection{Permeability}

The influences of the dosages of SP, W/B and dosage of VMA are highly significant on the permeability according to the ANOVA (Eq. 16). The dosage of SP is shown to exhibit the greatest effect as a primary variable on the permeability compared to W/B and dosage of and VMA (-7.7 vs. 2.38 or 1.15). However, the statistical analysis shows that the two-factor interaction of W/B.SP is highly significant and has the greatest effect on permeability. The interaction between W/B and VMA was significant and opposite effect to previous one (2.31 vs. -2.63). The increase in SP dosage has a greater influence on reducing the permeability than the increase in VMA dosage (-7.7 vs. 1.15). For example, the effect of increasing W/B ratio on permeability vs. the dosage of SP, when contents of VMA and LF were fixed at $0.05 \%$ and $28.5 \%$, respectively, or vs. the percentage of VMA when SP is fixed at $0.75 \%$ and the proportion of LF of $28.5 \%$, respectively, is shown in Fig. 6. For fixed dosage of VMA and the proportion of LF, the increase in SP led to an increase in permeability for lower W/B up to 0.38. However, for higher W/B (between 0.38 and 0.42), the increase of the dosage of SP resulted in a reduction in the permeability (Fig. 6(c)). This is due to the improved dispersion and packing of cement grains associated with greater SP dosage [20,43], the pores of the cement particles assembly are smaller for dispersed particles when SP is added. This led to an increase in the fluidity (Fig. 2) and particle packing (versus flocculated cement grains that have a lower packing density) can substantially reduce the tendency of water to percolate among cement grains under a given head, which reflects the permeability of the fresh grout. These results concur with the findings of other researchers [19, 20]. For lower W/B (lower than 0.38), the increase in VMA dosage exhibited a reduction in the permeability, however for higher W/B beyond 0.39 , the permeability seemed to 
increase as the dosage of VMA increased (Fig. 6(b)). Additionally, it is interesting to note that the permeability increase with W/C as reported by Picandet et al. [19].

\subsubsection{Compressibility}

Equation 17 shows the effect of the most significant parameters on compressibility. Only the dosage of SP, W/B and percentage of VMA had a significant effect on the compressibility as shown in Figure 7. The increase in SP or W/B led to an increase of compressibility, while the increase in VMA resulted in a decrease of compressibility. The SP dosage had the highest impact on the increase of compressibility followed by W/B, conversely, the VMA had the lowest effect in increasing the compressibility. For example, the increase in SP dosage has an approximately 1.7 times greater influence on increasing the compressibility than the reduction in W/B (-0.95 vs. -0.56$)$, and 2.4 times than increase in VMA (-0.95 vs. $+0.39)$.

Those results were expected as the increase of SP decrease the interaction forces between particles and then makes the grout more compressible [20, 22]. Also, an

increase in $\mathrm{W} / \mathrm{C}$ decreases the number of contacts within the network of cement particles increasing the compressibility of the material.

While increasing the SP dosage contributed to reducing the compressibility, the results herein showed that VMA had an opposite effect. Fig. 7 (a) and (b) shows the isoresponses of compressibility of W/B versus SP when the percentage of LF was $28.5 \%$ and VMA dosage of $0.05 \%$, and W/B versus VMA when SP is fixed at $0.75 \%$ and LF at $28.5 \%$, respectively.

\subsection{Discussion of the effect of VMA, SP, LF and W/B}

The increase of dosage of VMA led to a reduction of mini-slump and an increase in plate cohesion, yield stress, plastic viscosity, permeability and compressibility. This can be attributed to the intertwining and entanglement of VMA polymer chains and the association of water between adjacent chains $[9,10,13]$. At low shear, and especially at high concentrations, the intertwining of VMA chains can exhibit an increase in the apparent viscosity $[9,13]$. The higher viscosity of VMA which had high molecular weight may also be attributed to higher water retention of polymers. The factors that influence flow are described by Darcy's Law where the 
flow rate is inversely proportional to fluid viscosity. Thus, VMA increased the viscosity of the cement grout and improved the water retention. It was reported by Pourchez et al. [10] that the higher molecular weight of cellulose ethers, the higher water retention obtained of the mix.

An increase in SP dosage resulted in a reduction of the plate cohesion, yield stress, plastic viscosity, permeability and compressibility while the mini-slump (fluidity) is improved. This was due to higher surface coverage of binder particles by SP and consequently weaker van der Waals attraction between the particles. Therefore, lower forces are needed to disperse the particles and lower cohesivity [38]. This can be attributed to greater steric repulsions among cement particles that react with SP, leading to a better deflocculation of the particles in the paste and thus reducing the plastic viscosity. The effects of SP and VMA on cement grout correspond with the findings reported by other researchers $[9,10,11,13,14]$.

In case of an increase LF proportion, while VMA, SP and W/B were kept constant, it led to an increased mini-slump, while the plate cohesion, yield stress, and plastic viscosity were reduced. This was due to none reaction of LF particles as resulting in an increase of water needed for lubrification of grout. These results concord with other findings [44].

SP dosage has a significant effect on the permeability and compressibility due to the flocculation state of cement particles: When SP is added, the cement particles are more dispersed reducing the pore diameter and therefore the permeability. Similar findings have been reported in the literature $[19,20]$.

\subsection{Desirability functions for optimisation}

The numerical optimization for the performance characteristics of mortar was carried out for two examples having different criteria. Optimisation analysis have been performed for a combination of factor levels considered in this study that simultaneously satisfy the requirements of each response selected in the optimisation. The simultaneous optimisation for each response has a low and high value assigned to each goal. From the numerical optimisation, the goal for responses is one of five cases: none, maximum, minimum, target, or in a specified range. Each goal is assigned a weight between one (least important) and five (most important). Factors 
W/B, LF, SP and VMA are included in the optimisation, at their design range which is: as a maximum or minimum of a target goal. The goals are then combined into an overall desirability function, which reflects the desirability ranges for each response selected in the numerical optimisation [45]. The values of desirability function are ranged from zero to one for any given response. Goal desired begins at a random starting point and proceeds up the steepest slope to a maximum value. In same case, there may be two or more maximum values because of the curvature of the response surfaces and their combination with the desirability function. The value equals to one within the experimental domain represents the ideal case whereas zero may indicate that one or more responses fall outside the desirable limits. To illustrate this concept, Table 6 summarises the goals and weights for the measured responses selected in this study (mini-slump, cohesion plate, yield stress, plastic viscosity, permeability and compressibility.

Two examples are illustrated in this paper; the solutions of the desirability function are summarised in Table 6 and contours of these desirability functions are plotted in Figures 8 and 9. In Example 1, the mix parameters (W/B, LF, SP, VMA) were kept within the experimental ranges. In Example 2, both SP and VMA were minimised and W/B and LF were kept within the range. At dosage of VMA of $0.02 \%$ and LF of $45 \%$, the response surface in Figure 8 indicated for example 1 that the desirability function increased with an increase in SP and a reduction of W/B ratio. When four parameters were in the range to maximize the fluidity, plastic viscosity and compressibility while minimising cohesion, yield stress, and permeability (Table 6), the desirability function was 0.695 (Figure 8). The solution of the desirability function has been changed in case of example 2 when different goals or weights have been selected for the numerical optimisation by minimising SP and VMA dosages and keeping the goals and weight for all criteria similar to those in Example 1. In this case of example 2, the optimum solution for the desirability function became lower at 0.611 and was achieved with $0.82 \%$ SP and $0.02 \%$ VMA with LF of $12 \%$ and W/B of 0.42 (Figure 9).

\section{Conclusions}

The influence of different variables water/binder ratio, dosages of superplasticiser and viscosity modifying admixture, and the percentage of limestone 
filler on rheology properties and hydro-mechanical behaviour (permeability and compressibility) of cement grout were investigated. Based on the results presented in this paper, the following conclusions can be drawn:

1) W/B exhibited a significant effect on mini-slump, permeability and compressibility. The increase in $\mathrm{W} / \mathrm{B}$ ratio led to an increase in mini-slump and permeability, compressibility and reduced the plate cohesion.

2) The mini-slump, plate cohesion meter, and yield value of grouts are dominated primarily by the dosage of SP. The increase in the SP dosage led to an increase in mini-slump and a reduction in plate cohesion meter, yield value, and plastic viscosity. However, the permeability seemed to reduce when the SP dosage increased and increased when W/B increased. Permeability also reduced when VMA increased for low W/B, and increased with higher W/B and SP.

3) The viscosity modifying agent significantly affected the measured properties of this study. The increase in VMA dosage is shown to exhibit a reduction in minislump and an increase in plate cohesion meter, yield stress and plastic viscosity. For low W/B, the increase in VMA dosage reduced the permeability and compressibility, and increased it when W/B is higher.

4) For a given W/B, and dosages of SP and VMA, the mini-slump increased when the proportion of LF increased, while the plate cohesion meter, yield value, and plastic viscosity reduced. The LF replacement of cement had any effect on permeability and compressibility.

5) The numerical optimisation examples showed that the obtained response of the desirability function for testing the variables may change depending on the specified goals selected in the optimisation.

\section{References}

[1] Gustafson G., Stille H. Stop criteria for cement grouting. Felsbau: Zeitschrift für Geomechanik und Ingenieurgeologie im Bauwesen und Bergbau 2005;25:62-68.

[2] Shiotani T., Momoki S., Chai H., Aggelis DG. Elastic wave validation of large concrete structures repaired by means of cement grouting. Construction and Building Materials 2009;23:2647-2652.

[3] Warner J. Practical handbook of grouting: soil, rock, and structures. 2004; John Wiley \& Sons 
[4] Vintzileou E., Tassios TP. Three-leaf stone masonry strengthened by injecting cement grouts. Journal of Structural Engineering 1995;121:848-856

[5] Rosquoët F., Alexis A., Khelidj A., Phelipot A. Experimental study of cement grout: Rheological behavior and sedimentation. Cement and Concrete Research $2003 ; 33: 713-722$

[6] Rabbat BG., Russell HG. Friction coefficient of steel on concrete or grout. Journal of Structural Engineering 1985;111:505-515.

[7] Sonebi M., Lachemi M., Hossain KMA. Optimisation of rheological parameters and mechanical properties of superplasticised cement grouts containing metakaolin and viscosity modifying admixture. Construction and Building Materials Journal 2013;38(1): 126-138.

[8] Sonebi M., García-Taengua E., Hossain KMA., Khatib J., Lachemi M. Effect of nanosilica addition on the fresh properties and of mortars with fly ash and superplasticiser. Construction and Building Materials Journal. 2015;84:269-276.

[9] Khayat KH., Yahia A. Effect of welan gum-high-range water reducer combinations on rheology of cement grout. ACI Materials Journal. 1997;94(5):365-372.

[10] Pouchez J., Peschard A., Crosseau P., Guyonnet R., Guilhot B., Vallée F. HPMC and HEMC influence on cement hydration. Cement and Concrete Research 2006;36(2):288-294.

[11]Leemaann A., Winnefeld F. The effect of viscosity modifying agents on mortar and concrete. Cement and Concrete Composites 29(2) 2007 341-349.

[12]Lachemi M., Hossain KMA., Lambros V., Nkinamubanzi P.-C., Bouzoubaa N., Performance of new viscosity modifying admixtures in enhancing the rheological properties of cement paste. Cement and Concrete Research 34(2) 2004 185-193.

[13] Sonebi M., Rheological properties of grouts with viscosity modifying agents as diutan gum and welan gum incorporating pulverised fly ash. Cement and Concrete Research 36(9) 2006 1609-1618.

[14] Sonebi M., Optimization of cement grouts containing silica fume and viscosity modifying admixture. ASCE Materials Journal in Civil Engineering.2010; 22(4):332-342.

[15] Lowke D, Dini E, Perrot A, et al. Particle-bed 3D printing in concrete construction - Possibilities and challenges. Cement and Concrete Research 2018; https://doi.org/10.1016/j.cemconres.2018.05.018 
[16] Pierre A, Weger D, Perrot A, Lowke D. Penetration of cement pastes into sand packings during 3D printing: analytical and experimental study. Materials and Structures 2018;51:22. https://doi.org/10.1617/s11527-018-1148-5.

[17] Khayat KH, Yahia A, Sayed M. Effect of supplementary cementitious materials on rheological properties, bleeding, and strength of structural grout. ACI Materials Journal 2008;105(6):585-593.

[18] Saric-Coric M, Khayat KH, Tagnit-Hamou A. Performance characteristics of cement grouts made with various combinations of high-range water reducer and cellulose-based viscosity modifier. Cement and Concrete Research 2003; 33:1999-2008

[19] Picandet V, Rangeard D, Perrot A, Lecompte T (2011) Permeability measurement of fresh cement paste. Cement and Concrete Research 41:330-338

[20]Perrot A, Rangeard D, Picandet V, Mélinge Y (2013) Hydro-mechanical properties of fresh cement pastes containing polycarboxylate superplasticizer. Cement and Concrete Research 53:221-228

[21] Rangeard D, Perrot A, Picandet V, et al (2014) Determination of the consolidation coefficient of low compressibility materials: application to fresh cement-based materials. Materials and Structures 48:1475-1483

[22] Perrot A, Rangeard D (2017) Effects of mix design parameters on consolidation behaviour of fresh cement-based materials. Materials and Structures 50:117.

[23] Montgomery DC. Design and analysis of experiments. $6^{\text {th }}$ edition, John Wiley $\&$ Sons, 2005.

[24] Khayat K.H., Yahia A., Sonebi M. Applications of statistical models for proportioning underwater concrete. ACI Materials Journal 1999;96(6):634-640.

[25] Sonebi M., Medium strength self-compacting concrete containing fly ash: modelling using factorial experimental plans. Cement and Concrete Research 2004;34(7):1199-1208.

[26] European Committee for Standardization. EN 197-1: 2011 Cement - Part 1: Composition, specifications and conformity criteria for common cements. 2011.

[27] Kantro DL. Influence of water reducing admixtures on properties of cement paste - a miniature slump test. Cement Concrete and Aggregates. 1980;2(2):95-102.

[28] Lombardi G. The Role of cohesion in the cement grouting of rock. Proceedings of Fifteenth Congress on Large Dams. International Commission on Large Dams, Q.53, R.B. 1985;(3):235-261. 
[29] Khayat KH, Mladenka S-C, and Frank L. Influence of Thixotropy on Stability Characteristics of Cement Grout and Concrete. ACI Materials Journal 2002;99(3):105:234-241.

[30]Ferguson J., Kemblowski Z. Applied fluid rheology. Elsevier Applied Science, London and New York, 1991;199-231.

[31] Wong H.S., Buenfeld N.R., Determining the water-cement ratio, cement content, water content and degree of hydration of hardened cement paste: Method development and validation on paste samples, Cement \& Concrete Research (2009), 39 (10) 957-965.

[32] Perrot A, Lecompte T, Khelifi H, et al. Yield stress and bleeding of fresh cement pastes. Cement and Concrete Research 2012;42:937-944

[33] Roussel N, Lemaître A, Flatt RJ, Coussot P. Steady state flow of cement suspensions: A micromechanical state of the art. Cement and Concrete Research 2010;40:77-84. https://doi.org/10.1016/j.cemconres.2009.08.026.

[34] Pierre A, Lanos C, Estellé P. Extension of spread-slump formulae for yield stress evaluation. Applied Rheology 2013;23:63849

[35] Roussel N, Coussot P. Fifty-cent rheometer for yield stress measurements: From slump to spreading flow. Journal of Rheology 2005;49:705-718. http://dx.doi.org/10.1122/1.1879041.

[36] Kashani A, San Nicolas R, Qiao GG, et al. Modelling the yield stress of ternary cement-slag-fly ash pastes based on particle size distribution. Powder technology 2014;266:203-209.

[37]Flatt R., Bowen R. Yodel: A Yield Stress Model for Suspensions, Journal of the American Concrete Society, 2006, https://doi.org/10.1111/j.15512916.2005.00888.x.

[38] Lowke D. Interparticle forces and rheology of cement based suspensions. Proceedings of the NICOM3 - Nanotechnology in Construction, Prague, 2009:295-301.

[39] Negro C., Sánchez LM., Fuente A., Blanco Á., Tijero J. Polyacrylamide induced flocculation of a cement suspension - Chemical Engineering Science 61(8), 2006 2522-2532.

[40] Brumaud C., Baumann R., Schmitz M., Radler R.. Roussel N. Cellulose ethers and yield stress of cement pastes, Cement and Concrete (55) 2014 14-21. 
[41]Palacios P., Flatt R. , 20 - Working mechanism of viscosity-modifying admixtures, in: P.-C. Aïtcin, R.J. Flatt (Eds.), Science and Technology of Concrete Admixtures, Woodhead Publishing, 2016: 415-432.

[42] Krieger, I.M., \& Dougherty T.J. A mechanism for non-Newtonian flow in suspensions of rigid spheres. Transactions of the Society of Rheology, 1959,3(1), $137-152$

[43]Zingg A, Holzer L, Kaech A, et al. The microstructure of dispersed and nondispersed fresh cement pastes - New insight by cryo-microscopy. Cement and Concrete Research 2008;38:522-529. http://dx.doi.org/10.1016/j.cemconres.2007.11.007.

[44] Neto SN., Campitelli VC., The influence of limestone additions on the rheological properties and water retention value of portland cement slurries, ASTM Spec Tech Publ 1064 1990; 24-29.

[45] Harington J. The Desirability function. Industrial Quality Control 21, 1965, 494498. 


\section{Table 1}

Factors and levels considered

\begin{tabular}{ll}
\hline Factor & Levels \\
\hline W/B & $0.35,0.39,0.42$ \\
LF $(\%)$ & $12,28.5,45$ \\
VMA dosage & $0.02 \%, 0.045 \%, 0.07 \%$ \\
SP dosage & $0.3 \%, 0.75 \%, 1.2 \%$ \\
\hline
\end{tabular}

Table 2

Mix proportions of grouts

\begin{tabular}{|c|c|c|c|c|c|}
\hline & Ref. & W/B & LF (\%) & VMA (\%) & SP (\%) \\
\hline \multirow{5}{*}{$\begin{array}{c}\text { Selected } \\
\text { mixes }\end{array}$} & 1 & 0.42 & 12.0 & 0.07 & 0.3 \\
\cline { 2 - 6 } & 2 & 0.35 & 12.0 & 0.02 & 0.3 \\
\cline { 2 - 6 } & 3 & 0.42 & 12.0 & 0.02 & 1.2 \\
\cline { 2 - 6 } & 4 & 0.35 & 12.0 & 0.07 & 1.2 \\
\cline { 2 - 6 } & 5 & 0.42 & 45.0 & 0.02 & 0.3 \\
\cline { 2 - 6 } & 6 & 0.35 & 45.0 & 0.07 & 0.3 \\
\hline \multirow{5}{*}{ Centre points } & 0.42 & 45.0 & 0.07 & 1.2 \\
\hline & 8 & 0.35 & 45.0 & 0.02 & 1.2 \\
\hline & 9 & 0.39 & 28.5 & 0.045 & 0.75 \\
\cline { 2 - 6 } & 11 & 0.39 & 28.5 & 0.045 & 0.75 \\
\hline & 12 & 0.39 & 28.5 & 0.045 & 0.75 \\
\hline
\end{tabular}


Table 3

Chemical and physical properties of cement and limestone filler

\begin{tabular}{|c|c|c|}
\hline \multirow[b]{2}{*}{ Composition } & Cement & Limestone Filler \\
\hline & \multicolumn{2}{|c|}{ Percentage by mass, $\%$} \\
\hline $\mathrm{CaO}$ & 63.7 & -- \\
\hline $\mathrm{SiO}_{2}$ & 20.8 & -- \\
\hline $\mathrm{Al}_{2} \mathrm{O}_{3}$ & 5.0 & -- \\
\hline $\mathrm{Fe}_{2} \mathrm{O}_{3}$ & 3.2 & -- \\
\hline $\mathrm{MgO}$ & 2.6 & 0.2 \\
\hline $\mathrm{Na}_{2} \mathrm{O}$ eq. & 0.39 & -- \\
\hline Free $\mathrm{CaO}$ & 1.6 & -- \\
\hline LOI & 0.65 & -- \\
\hline $\mathrm{CaCO}_{3}$ & -- & 99 \\
\hline \multicolumn{3}{|l|}{ Physical proerties } \\
\hline Specific gravity & 3.14 & 2.65 \\
\hline Specific surface area, $\mathrm{cm}^{2} / \mathrm{g}$ & 3850 & -- \\
\hline
\end{tabular}


Table 4

Results of rheology, permeability and compressibility

\begin{tabular}{|c|c|c|c|c|c|c|}
\hline \multirow{2}{*}{ Ref. } & \multirow{2}{*}{$\begin{array}{c}\text { Mini- } \\
\text { slump }\end{array}$} & $\begin{array}{c}\text { Cohesion } \\
\text { meter }\end{array}$ & $\begin{array}{c}\text { Yield } \\
\text { stress }\end{array}$ & $\begin{array}{c}\text { Plastic } \\
\text { viscosity }\end{array}$ & Permeability k & \\
\hline & $(\mathrm{mm})$ & $(\mathrm{mm})$ & $(\mathrm{Pa})$ & $($ Pa.s $)$ & $(\mathrm{m} / \mathrm{s})$ & \\
\hline 1 & 62 & 1.41 & 8.4 & 0.40 & $3.0210^{-7}$ & 0.166 \\
\hline 2 & 77 & 1.35 & 11.4 & 0.52 & $1.06210^{-7}$ & 0.137 \\
\hline 3 & 180 & 0.08 & 1.8 & 0.11 & $2.6010^{-7}$ & \\
\hline 4 & 77 & 1.07 & 10.8 & 1.17 & $3.6410^{-7}$ & 0.151 \\
\hline 5 & 118 & 0.57 & 11.3 & 0.17 & $2.110^{-7}$ & 0.122 \\
\hline 6 & 65 & 1.74 & 4.4 & 0.79 & $1.5110^{-7}$ & 0.111 \\
\hline 7 & 173 & 0.16 & 5.5 & 0.13 & $7.2910^{-8}$ & 0.198 \\
\hline 8 & 142 & 0.08 & 2.5 & 0.17 & $7.3010^{-8}$ & 0.165 \\
\hline 9 & 112 & 0.27 & 9.1 & 0.29 & $1.4110^{-7}$ & 0.147 \\
\hline 10 & 116 & 0.32 & 9.8 & 0.27 & $1.2010^{-7}$ & 0.162 \\
\hline 11 & 126 & 0.36 & 10.2 & 0.33 & $1.5110^{-7}$ & 0.168 \\
\hline 12 & 113 & 0.45 & 11.0 & 0.35 & $1.4110^{-7}$ & 0.161 \\
\hline
\end{tabular}

Table 5

Repeatability of test parameters at the central point

\begin{tabular}{ccccccc}
\hline Tests & $\begin{array}{c}\text { Mini- } \\
\text { slump }\end{array}$ & $\begin{array}{c}\text { Plate } \\
\text { cohesion }\end{array}$ & $\begin{array}{c}\text { Yield } \\
\text { stress }\end{array}$ & $\begin{array}{c}\text { Plastic } \\
\text { viscosity }\end{array}$ & Permeability & Compressibility \\
\hline Mean (n=4) & $116.8 \mathrm{~mm}$ & $0.349 \mathrm{~mm}$ & $10.02 \mathrm{~Pa}$ & 0.31 Pa.s & $1.37 \mathrm{~m} / \mathrm{s}$ & 0.164 \\
$\begin{array}{c}\text { Coefficient of } \\
\text { variation (\%) }\end{array}$ & 4.8 & 15.6 & 5.2 & 8.3 & 8.2 & 4.8 \\
$\begin{array}{c}\text { Estimate error } \\
\text { 90\% confidence }\end{array}$ & 5.3 & 0.05 & 0.49 & 0.02 & 0.11 & 0.01 \\
limit) & $\mathrm{mm}$ & $\mathrm{mm}$ & $\mathrm{Pa}$ & $\mathrm{Pa} . \mathrm{s}$ & $\mathrm{m} / \mathrm{s}$ & \\
\hline
\end{tabular}


Table 6

Criteria, goals and goals' importance used in desirability (numerical optimization)

\begin{tabular}{|c|c|c|c|c|}
\hline \multirow[b]{2}{*}{ Criteria } & \multicolumn{2}{|c|}{ Example 1} & \multicolumn{2}{|c|}{ Example 2} \\
\hline & $\begin{array}{c}\text { Goal/ } \\
\text { Importance }\end{array}$ & $\begin{array}{c}\text { Solution }= \\
0.695\end{array}$ & $\begin{array}{c}\text { Goal/ } \\
\text { Importance }\end{array}$ & Solution $=$ \\
\hline \multicolumn{5}{|l|}{ Factors } \\
\hline $\mathrm{W} / \mathrm{B}$ & Within range & 0.35 & Within range & 0.42 \\
\hline $\operatorname{LF}[\%]$ & Within range & 45 & Within range & 12 \\
\hline $\mathrm{SP}[\%]$ & Within range & 1.2 & Minimise 1 & 0.82 \\
\hline VMA [\%] & Within range & 0.02 & Minimise 1 & 0.02 \\
\hline \multicolumn{5}{|l|}{ Responses } \\
\hline Mini-slump flow [mm] & Maximise 5 & 140 & Maximise 5 & 142 \\
\hline Plate cohesion [mm] & Minimise 1 & 0.085 & Minimise 1 & 0.180 \\
\hline Yield stress $[\mathrm{Pa}]$ & Minimise 1 & 2.6 & Minimise 1 & 2.3 \\
\hline Plastic viscosity [Pa.s] & Minimise 1 & 0.18 & Minimise 1 & 0.15 \\
\hline Permeability $[\mathrm{m} / \mathrm{s}]$ & Minimise 1 & $6.6210^{-8}$ & Minimise 1 & $1.0310^{-7}$ \\
\hline Compressibility & Maximise 5 & 0.165 & Maximise 5 & 0.611 \\
\hline
\end{tabular}




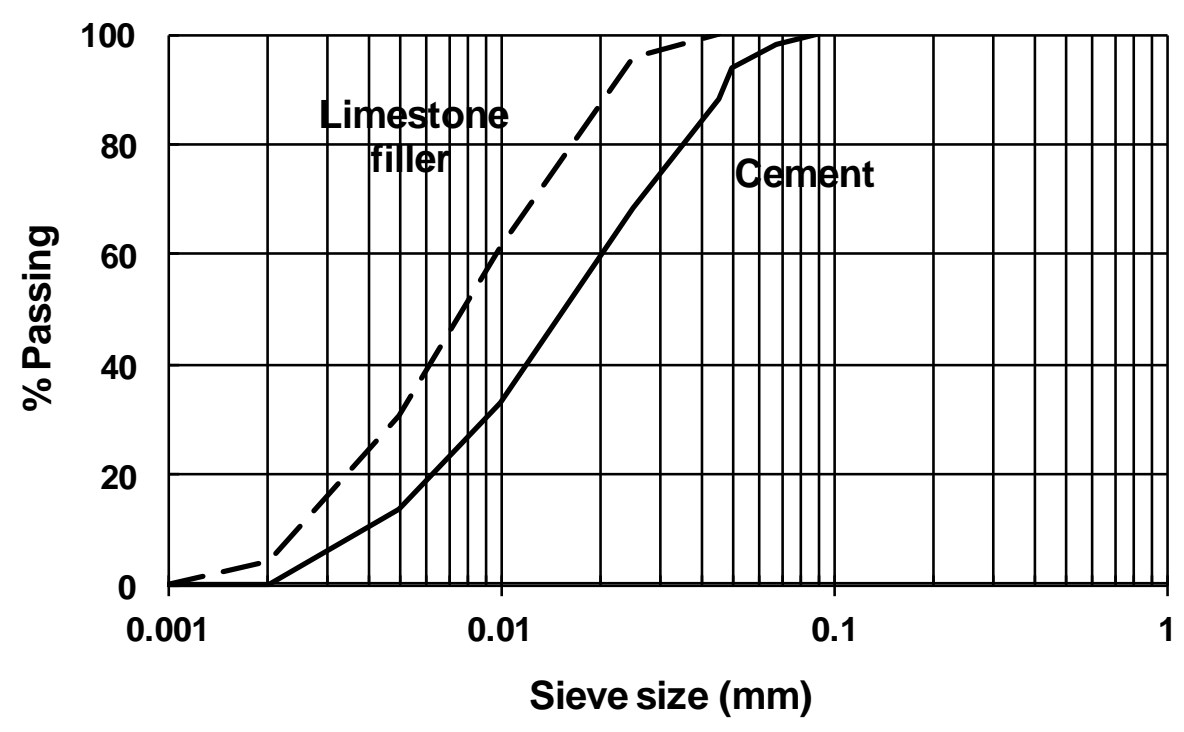

Fig 1. Particel size distribution of cement and limestone filler 


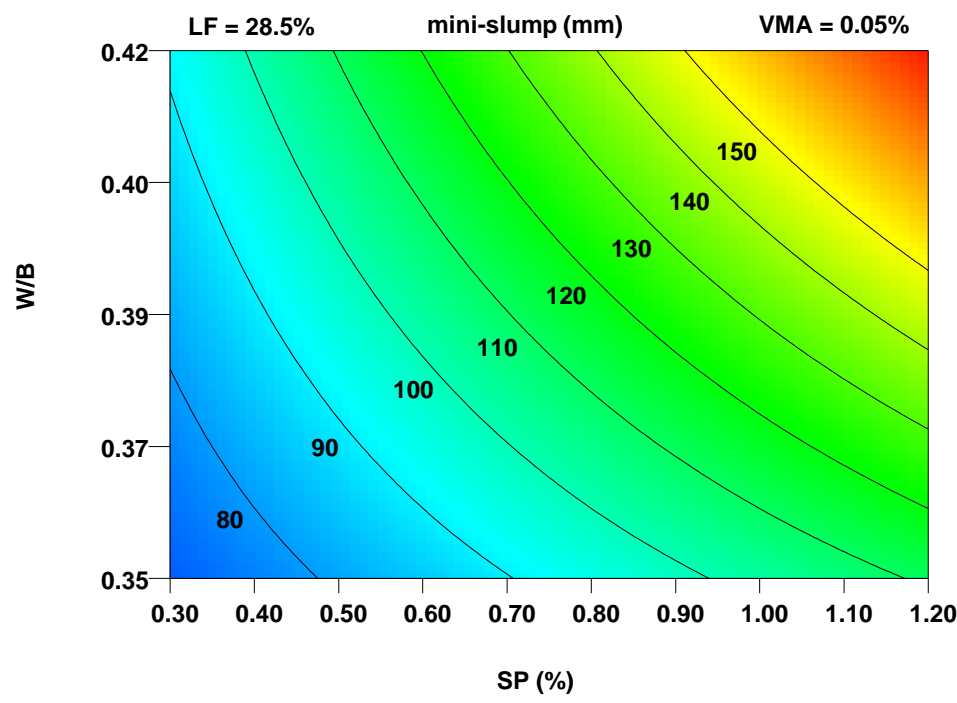

(a)

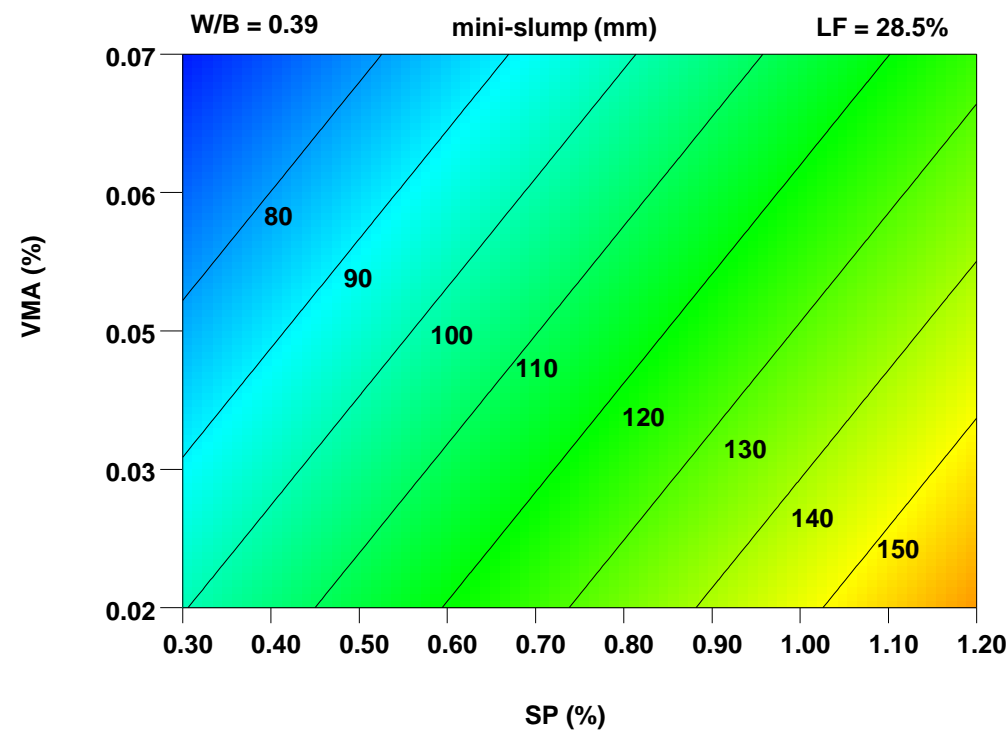

(b)

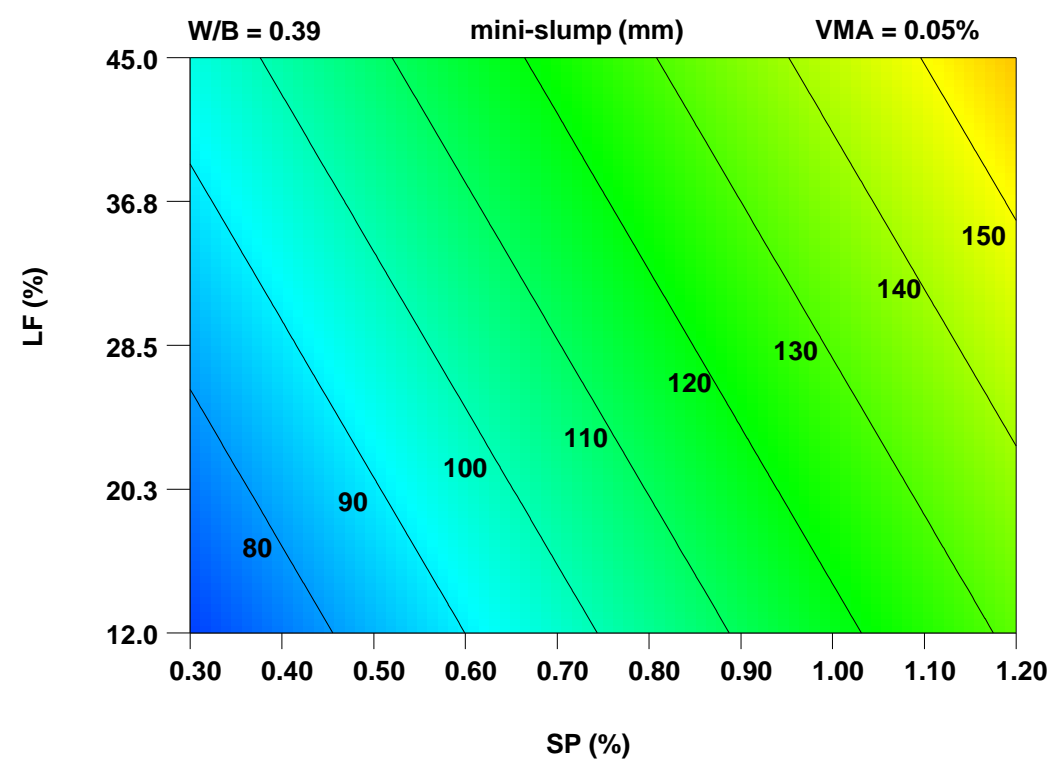

(c)

Fig 2. Isoresponses of mini-slump (a) SP vs. W/B, (b) SP vs. VMA, (c) SP vs. LF 

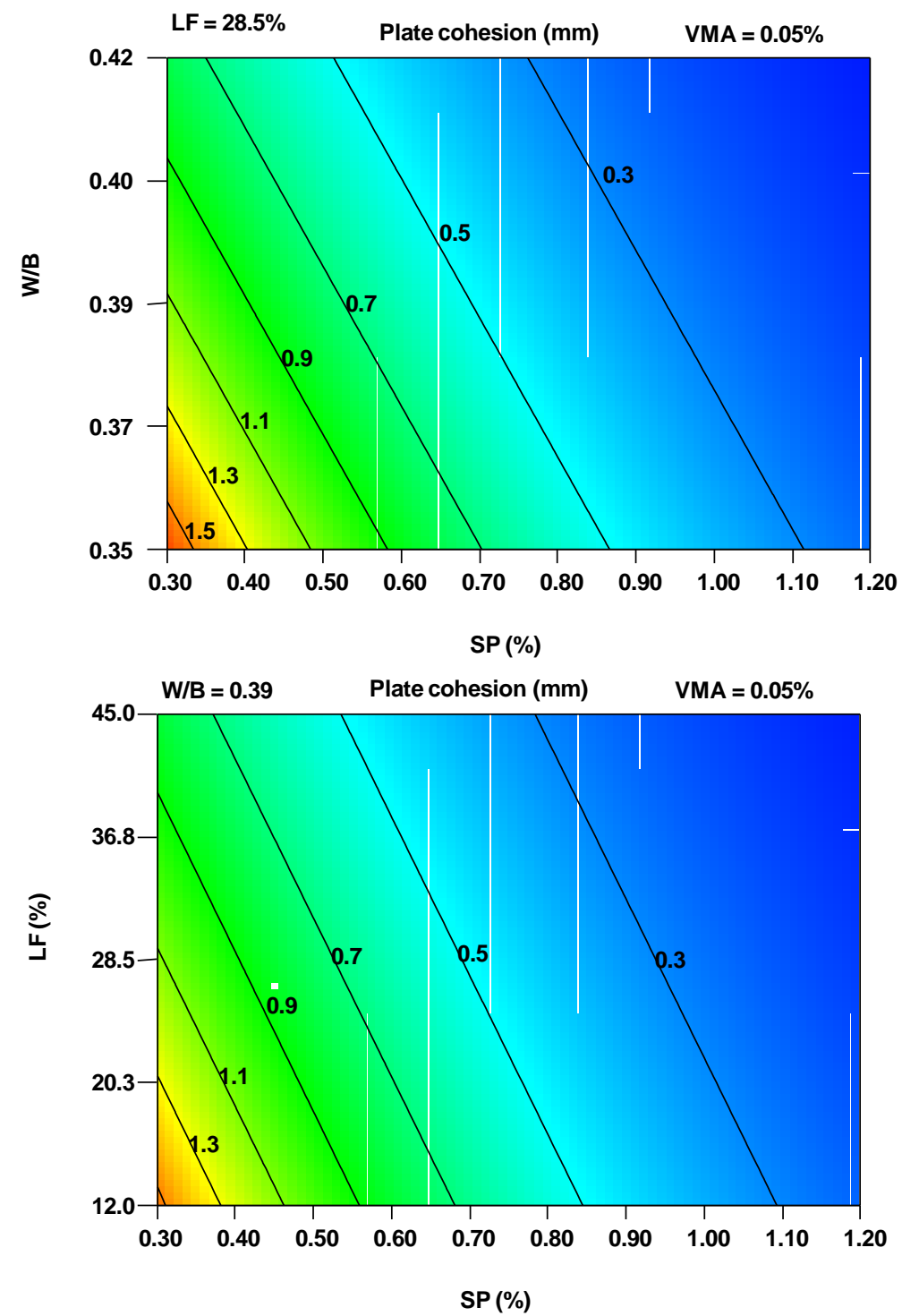

(a)

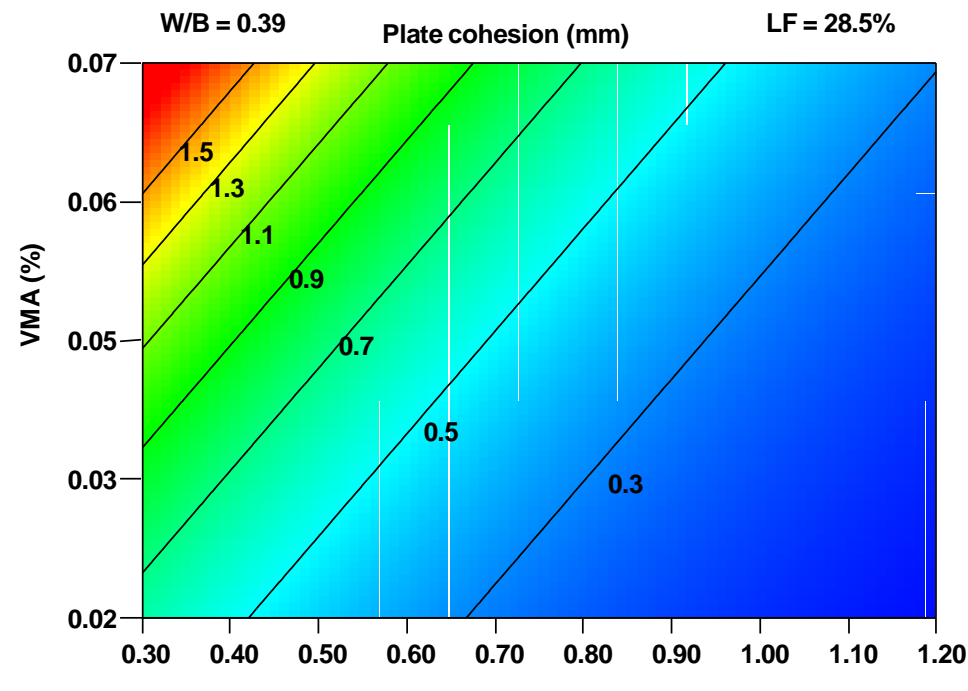

SP (\%)

(c)

Fig. 3. Isoresponses of plate cohesion (a) SP vs. W/B, (b) VMA vs. W/B, (c) LF vs. W/B 


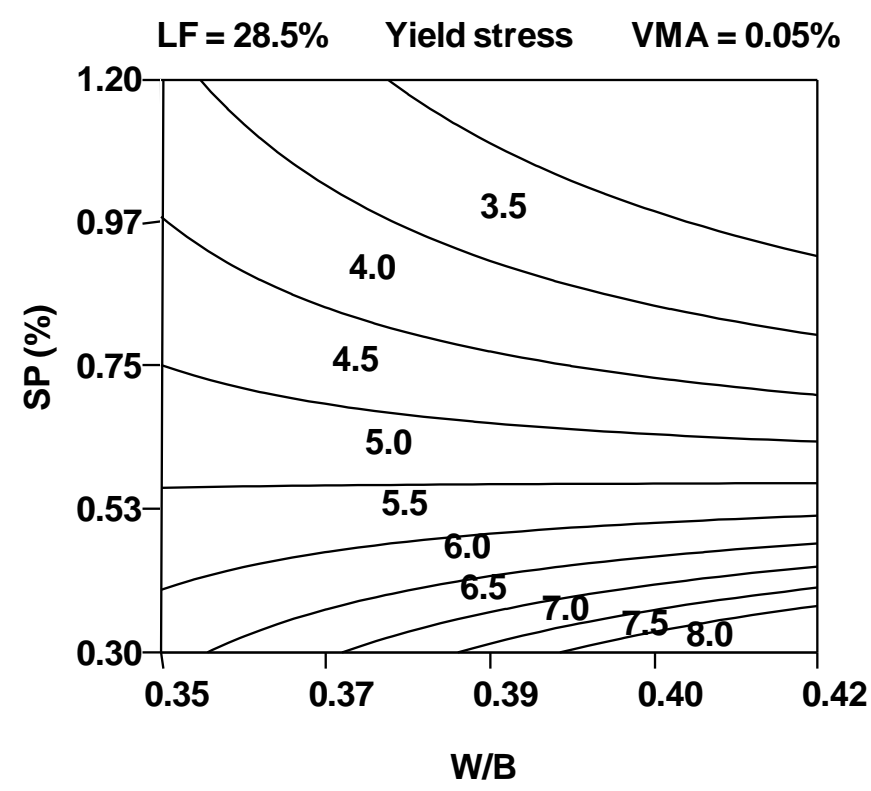

(a)
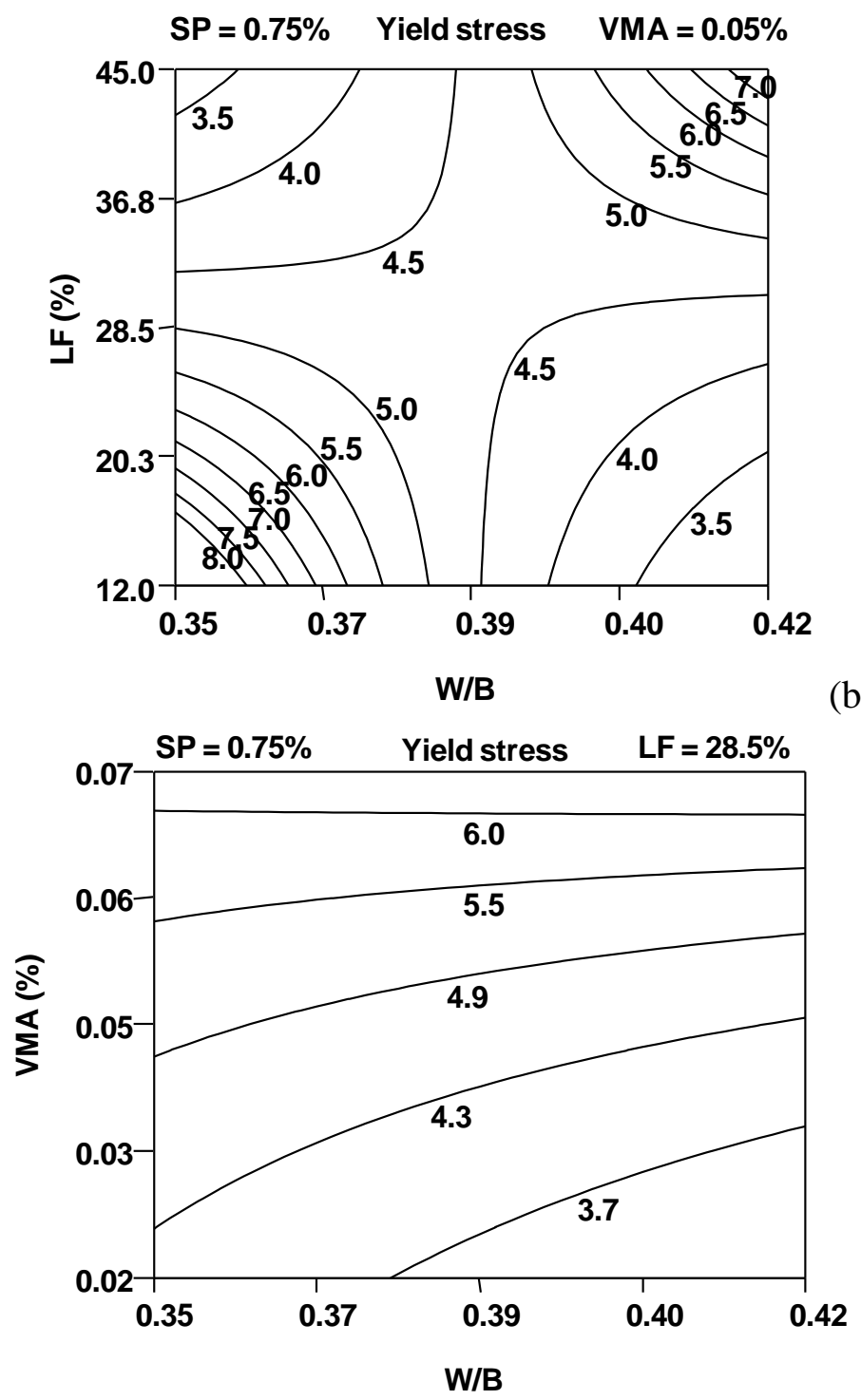

(b)

Fig. 4. Isoresponses of yield stress (a) W/B vs. SP, (b) W/B vs. LF, (c) W/B vs. VMA 


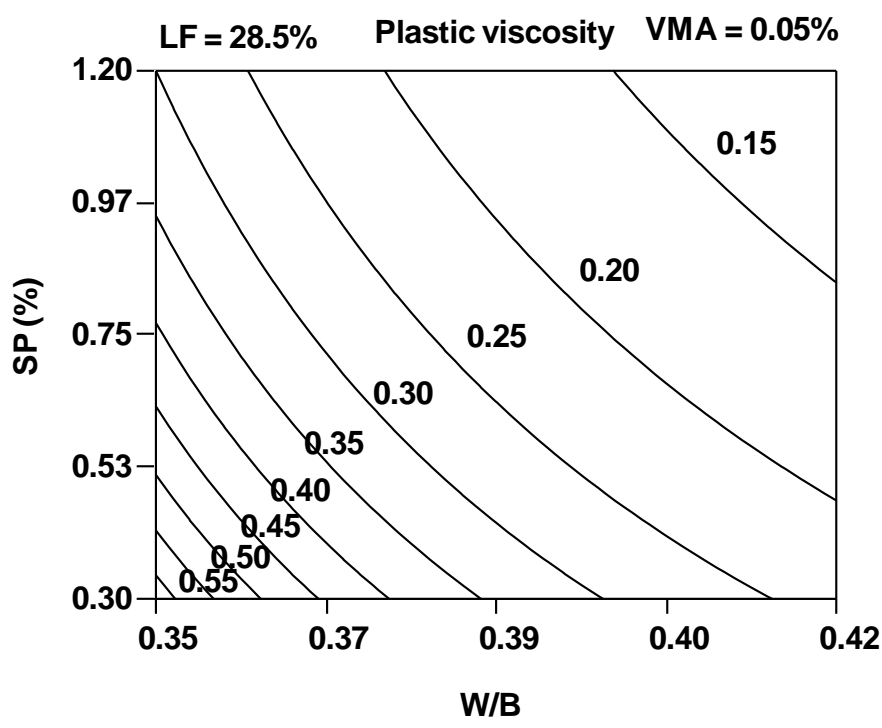

(a)

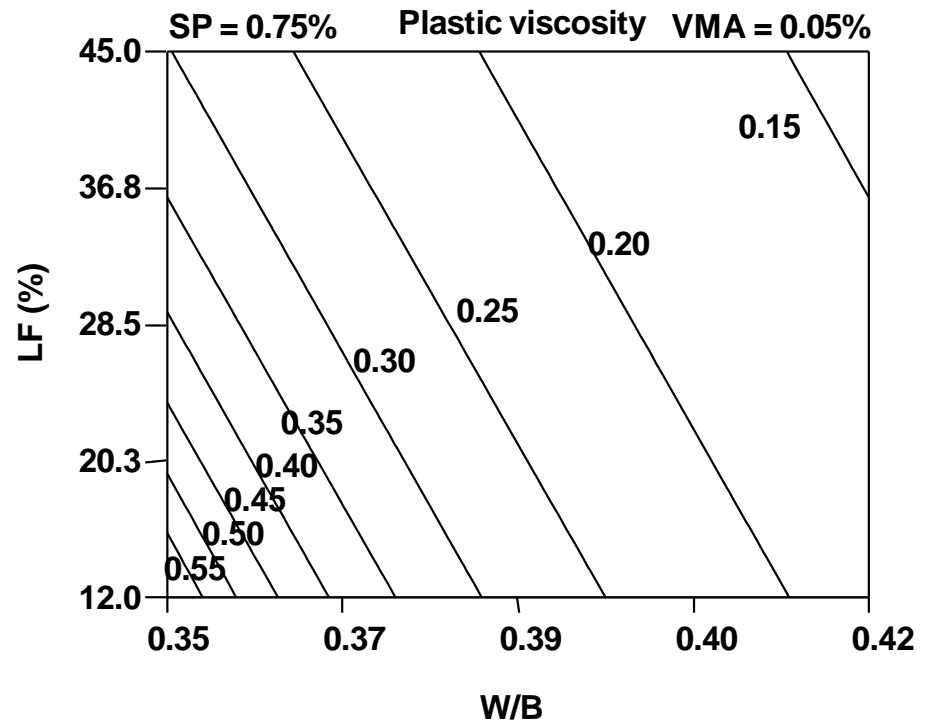

(b)

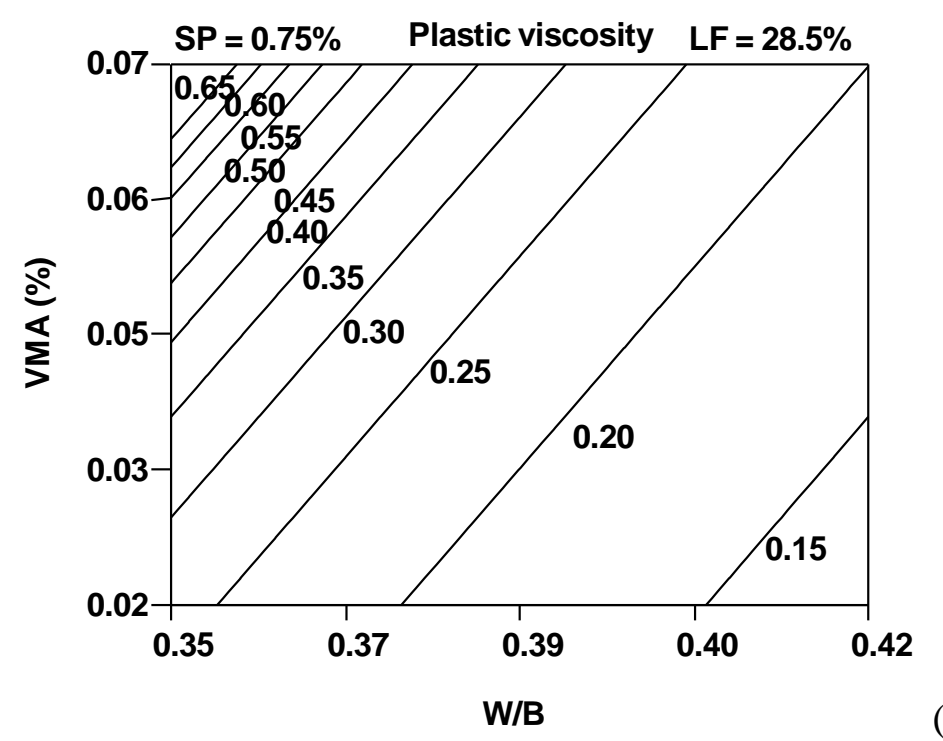

(c)

Fig. 5. Isoresponses of plastic viscosity (a) W/B vs. SP, (b) W/B vs. LF, (c) W/B vs. VMA 


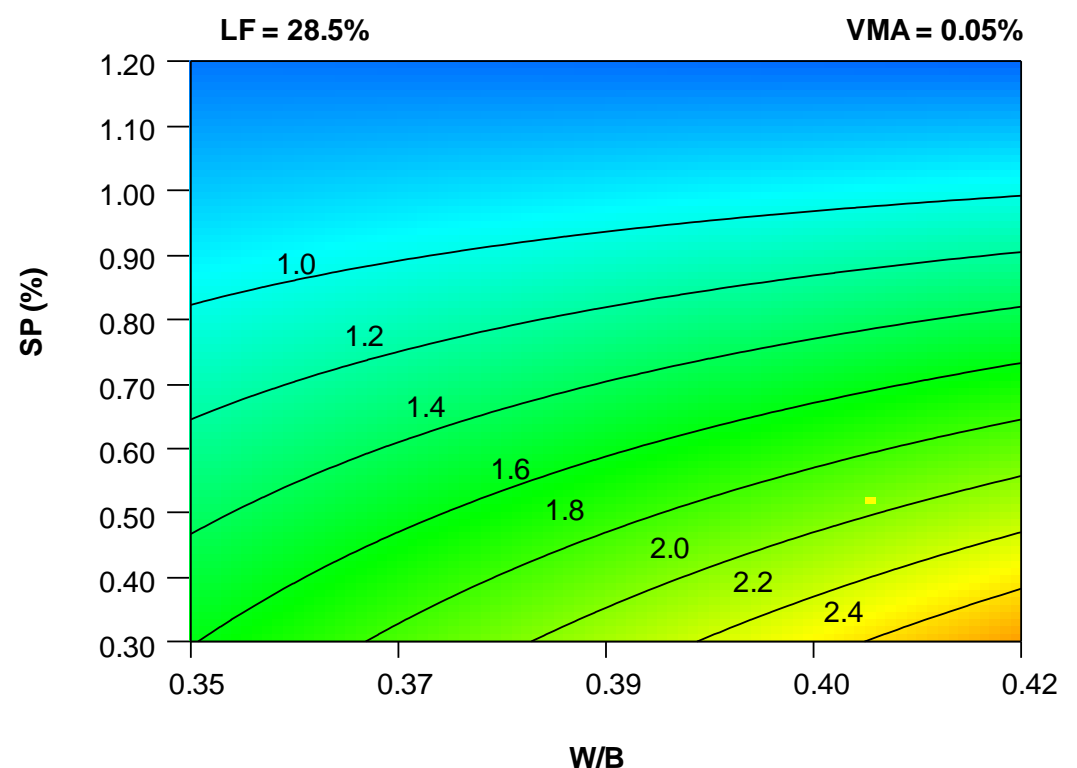

(a)

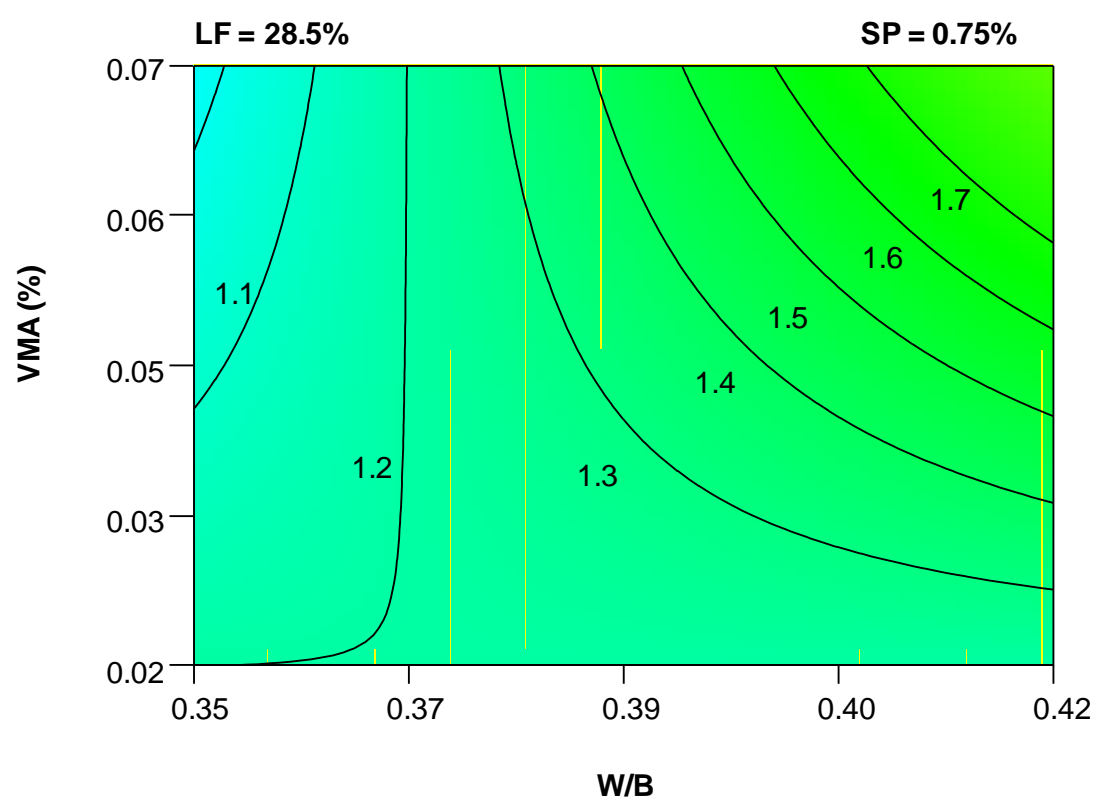

(b)

Fig. 6. Isoresponses of permeability $\times 10^{-7}$ (a) W/B vs. SP, (b) W/B vs. VMA 

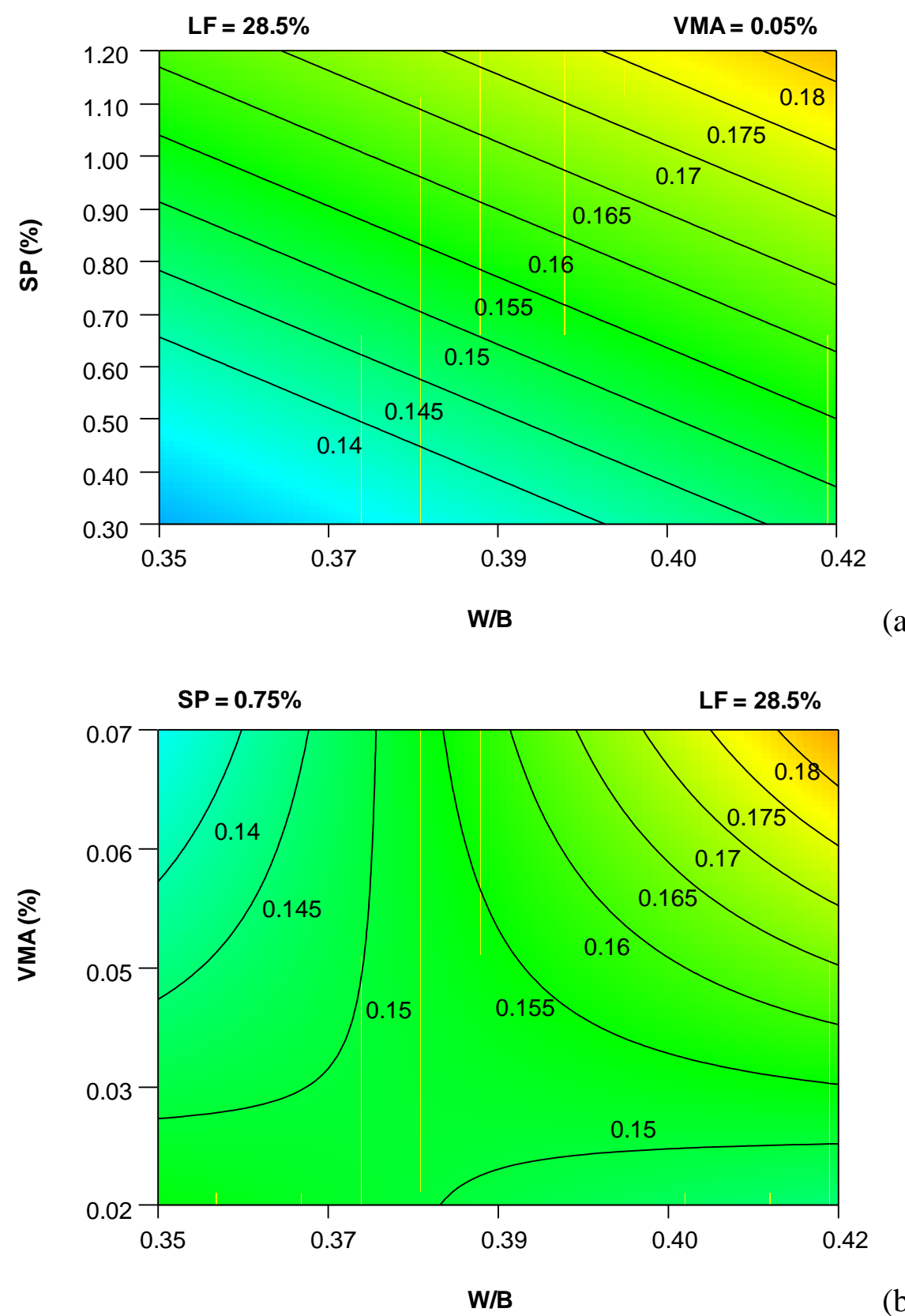

(a)

Fig. 7. Isoresponses of compressibility (a) W/B vs. SP, (b) W/B vs. VMA 


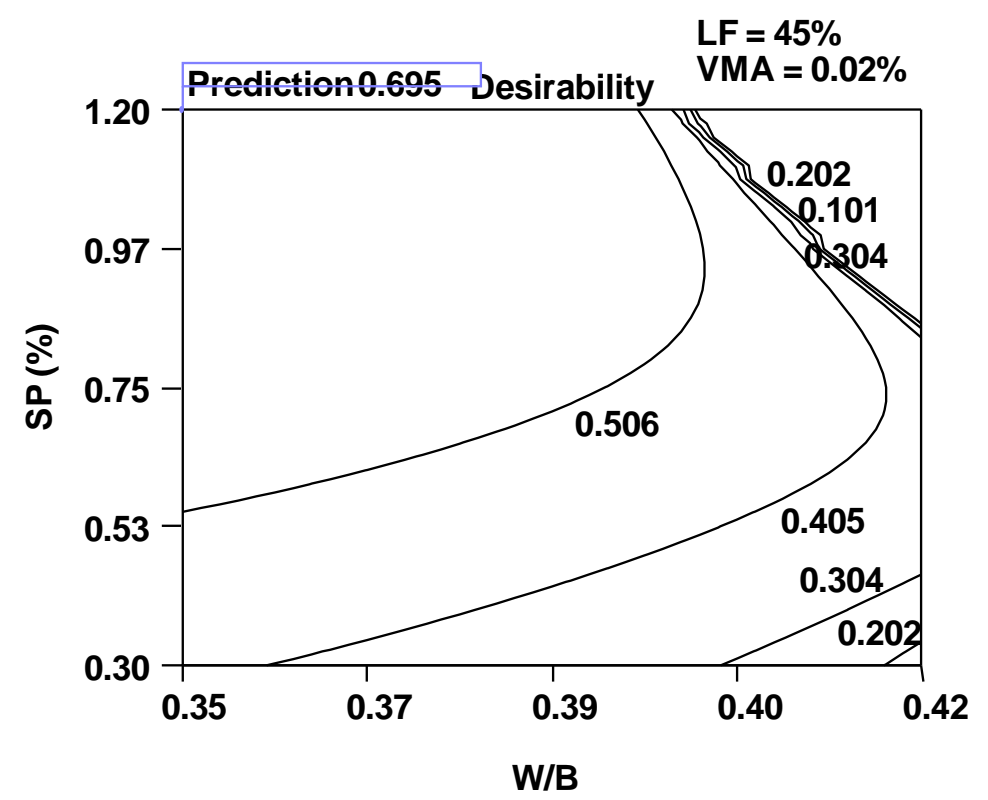

Fig. 8. Contour plots of the desirability function based on multi-parametric numerical optimization for grouts with all parameters in the range (Example 1)

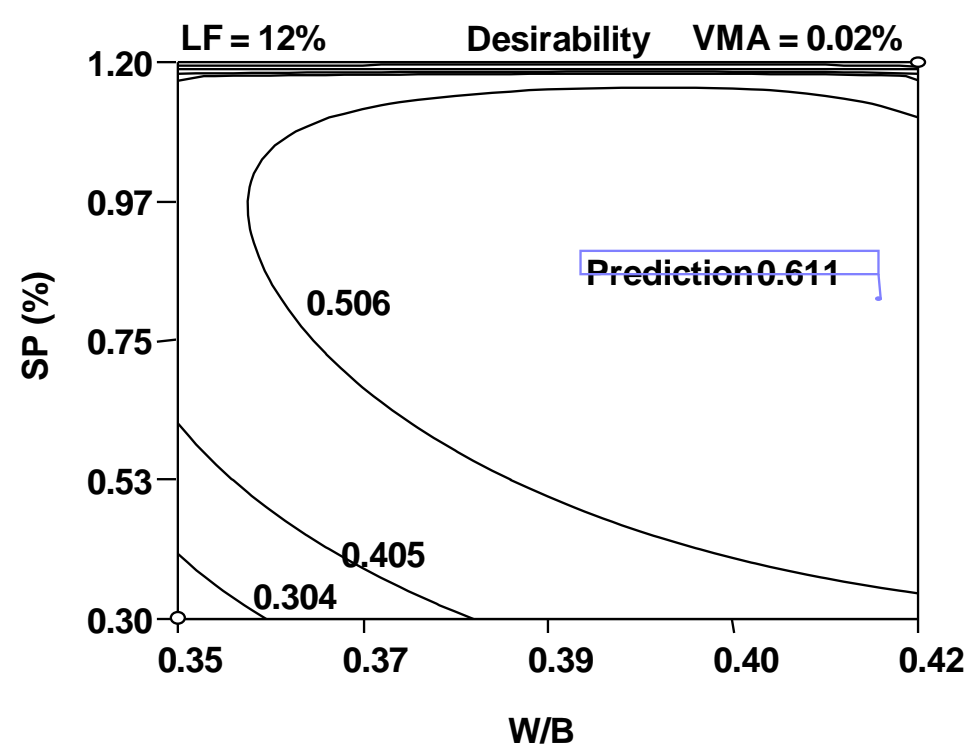

Fig. 9. Contour plots of the desirability function based on multi-parametric numerical optimization for grouts with minimise \% of SP and VMA (Example 2) 